\title{
Vascular Disease in Multiple Sclerosis: A Real Thing?
}

\author{
Maria Grazia Caprio* and Marcello Mancini \\ Institute of Biostructures and Bioimaging, National Research Council, via Tommaso De Amicis, Naples, Italy
}

*Corresponding author: Maria Grazia Caprio, Institute of Biostructures and Bioimaging, National Research Council, via Tommaso De Amicis-95-80145, Naples, Italy, Tel: +39 081 2203411; Fax: +39081 2203498; E-mail: mariagrazia.caprio@ibb.cnr.it

Received date: Oct 05, 2016, Accepted date: Oct 10, 2016, Publication date: Oct 14, 2016

Copyright: (c) 2016 Caprio MG, et al. This is an open-access article distributed under the terms of the Creative Commons Attribution License, which permits unrestricted use, distribution, and reproduction in any medium, provided the original author and source are credited.

In recent years, great interest has been addressed to the association between vascular abnormalities and Multiple Sclerosis (MS) [1-8]. Many studies have shown that patients with MS have an increased cardiovascular risk and increased mortality related to stroke and cardiovascular disease compared to general population [9-13]. In addition, MS patients who had more than one cardiovascular risk factor at diagnosis were more likely to develop disabilities $[2,14,15]$.

Some authors have recently demonstrated the existence of the cerebral perfusion abnormalities in MS patients [16]. The breakdown of the blood-brain barrier is a constant characteristic of MS focal lesions and is demonstrated by MR imaging $[17,18]$. Chronic lesions in MS patients, studied by Perfusion-weighted MRI, showed reduced perfusion, in contrast with enhancing lesions that showed increased perfusion. The presence of ischemic central focal areas, suggests that ischemia plays an important role in the development of some focal lesions in multiple sclerosis $[19,20]$.

Law et al. [21] demonstrated a reduction in cerebral blood flow and a prolonged transit time in the periventricular regions of normal appearing white matter (NAWM) in MS patients than in controls. Other studies showed hypoperfusion in different regions (NAWM, and deep GM) independently of clinical MS form [22,23]. These changes in cerebral perfusion were correlated with clinical disability and neuropsychological impairment [24].

Moreover, many authors have studied the possible association between abnormal venous drainage and MS and have shown that multiple sclerosis is often associated with hemodynamic abnormalities and vascular changes [25-32].

Recently Zamboni introduced the concept of chronic cerebrospinal venous insufficiency (CCSVI) as a vascular condition characterized by anomalies of the main extra-cranial cerebrospinal venous outflow routes that interfere with normal venous outflow in patients with multiple sclerosis. This condition could cause an increase in iron vein deposit resulting in the characteristic inflammation of tissues of the MS [30,33-34]. However the studies that used Echo-color Doppler for the detection of CCSVI demonstrate too high variability of results. Therefore ultrasound is not a good screening methodology and further studies are needed to determine techniques that can measure venous cerebral outflow and are less operator-dependent and more objective.

Macro and micro circulation alterations can cause changes in the endothelial cells, resulting in immune-mediated reactions and inflammatory response. The autoimmune inflammation can lead to iron deposition and leukocyte infiltration. Furthermore the consequent production of vascular mediators by the immune system cells and endothelial activation and neovascularization can cause changes in the microcirculation [35-38]. This multiple vascular risk factors together with inflammatory factors, through interactions with neuronal cells and components of myelin, could lead to increased permeability of the blood brain barrier and neurovascular uncoupling up to neuronal damage. However, it is yet to be determined if the vascular damage is the primary causal factor of neurological disease, or secondary to inflammation-autoimmunity.

The frequent association between MS and vascular diseases suggests that vascular changes, might contribute to neuronal or degenerative dysfunction in patients with MS. However, the results in the literature are often discordant both as regards the association between vascular and brain damage in neurological diseases, both for the correlation between vascular disease and disability. Several studies are mostly "case-control" and there are no multi population studies.

In conclusion, more studies are needed to verify the existence of a real correlation between vascular damage and degenerative and demyelinating neurological diseases.

\section{References}

1. Noseworthy JH, Lucchinetti C, Rodriguez M, Weinshenker BG (2000) Multiple sclerosis. N Engl J Med 343: 938-952.

2. Tettey P, Simpson S, Taylor BV, van der Mei IA (2014) Vascular comorbidities in the onset and progression of multiple sclerosis. J Neurol Sci 347: 23-33.

3. Karmon Y, Ramanathan M, Minagar A, Zivadinov R, WeinstockGuttman B (2012) Arterial, venous and other vascular risk factors in multiple sclerosis. Neurol Res 34: 754-760.

4. Christiansen CF, Christensen S, Farkas DK, Miret M, Sørensen HT, et al. (2010) Risk of arterial cardiovascular diseases in patients with multiple sclerosis: a population-based cohort study. Neuroepidemiology 35: 267-274.

5. Caprio MG, Russo C, Giugliano A, Ragucci M, Mancini M (2016) Vascular disease in patients with multiple sclerosis: A review. J Vasc Med Surg 4: 259.

6. Bastianello S, Romani A, Viselner G, Tibaldi EC, Giugni E, et al. (2011) Chronic cerebrospinal venous insufficiency in multiple sclerosis: clinical correlates from a multicentre study. BMC Neurol 11: 132.

7. Mancini M, Lanzillo R, Liuzzi R, Di Donato O, Ragucci M, et al. (2014) Internal jugular vein blood flow in multiple sclerosis patients and matched controls. PLoS One 9: e92730.

8. Mancini M, Morra VB, Di Donato O, Maglio V, Lanzillo R, et al. (2012) Multiple sclerosis: cerebral circulation time. Radiology 262: 947-955.

9. Koch-Henriksen N, Brønnum-Hansen H, Stenager E (1998) Underlying cause of death in Danish patients with multiple sclerosis: results from the Danish Multiple Sclerosis Registry. J Neurol Neurosurg Psychiatry 65: 56-59.

10. Hirst C, Swingler R, Compston DA, Ben-Shlomo Y, Robertson NP (2008) Survival and cause of death in multiple sclerosis: a prospective population-based study. J Neurol Neurosurg Psychiatry 79: 1016-1021. 
11. Kang JH, Chen YH, Lin HC (2010) Comorbidities amongst patients with multiple sclerosis: a population-based controlled study. Eur J Neurol 17: 1215-1219.

12. Jadidi E, Mohammadi M, Moradi T (2013) High risk of cardiovascular diseases after diagnosis of multiple sclerosis. Mult Scler 19: 1336-1340.

13. Tseng CH, Huang WS, Lin CL, Chang YJ (2015) Increased risk of ischaemic stroke among patients with multiple sclerosis. Eur J Neurol 22: 500-506.

14. Marrie RA, Rudick R, Horwitz R, Cutter G, Tyry T, et al. (2010) Vascular comorbidity is associated with more rapid disability progression in multiple sclerosis. Neurology 74: 1041-1047.

15. Marrie RA, Horwitz R, Cutter G, Tyry T, Campagnolo D, et al. (2009) Comorbidity delays diagnosis and increases disability at diagnosis in MS. Neurology 72: 117-124.

16. Lanzillo R, Mancini M, Liuzzi R, Di Donato O, Salvatore E, et al. (2013) Chronic cerebrospinal venous insufficiency in multiple sclerosis: a highly prevalent age-dependent phenomenon. BMC Neurol 13: 20.

17. Paul F, Waiczies S, Wuerfel J, Bellmann-Strobl J, Dörr J, et al. (2008) Oral high-dose atorvastatin treatment in relapsing-remitting multiple sclerosis. PLoS One 3: e1928.

18. Wuerfel J, Paul F, Zipp F (2007) Cerebral blood perfusion changes in multiple sclerosis. J Neurol Sci 259: 16-20.

19. Wuerfel J, Bellmann-Strobl J, Brunecker P, Aktas O, McFarland H, et al. (2004) Changes in cerebral perfusion precede plaque formation in multiple sclerosis: a longitudinal perfusion MRI study. Brain 127: 111-119.

20. Rosso C, Remy P, Creange A, Brugieres P, Cesaro P, et al. (2006) Diffusion-weighted MR imaging characteristics of an acute strokelike form of multiple sclerosis. AJNR Am J Neuroradiol 27: 1006-1008.

21. Law M, Saindane AM, Ge Y, Babb JS, Johnson G, et al. (2004) Microvascular abnormality in relapsing-remitting multiple sclerosis: perfusion MR imaging findings in normal-appearing white matter. Radiology 231: 645-652.

22. Inglese M, Park SJ, Johnson G, Babb JS, Miles L, et al. (2007) Deep gray matter perfusion in multiple sclerosis: dynamic susceptibility contrast perfusion magnetic resonance imaging at 3 T. Arch Neurol 64: 196-202.

23. Varga AW, Johnson G, Babb JS, Herbert J, Grossman RI, et al. (2009) White matter hemodynamic abnormalities precede sub-cortical gray matter changes in multiple sclerosis. J Neurol Sci 282: 28-33.
24. Inglese M, Adhya S, Johnson G, Babb JS, Miles L, et al. (2008) Perfusion magnetic resonance imaging correlates of neuropsychological impairment in multiple sclerosis. J Cereb Blood Flow Metab 28: 164-117.

25. Cruveilhier J (1829-1842) Anatomie pathologique du corps humain. Baillière, Paris, France.

26. Reindfleisch E (1863) Histologisches detail zu der grauen degeneration von gehirn und rueckenmark. Arch Path Anat Physiol Klin Med 26: 474-483.

27. Tracy J, Putnam MD (1937) Evidences of vascular occlusion in multiple sclerosis and "encephalomyelitis". Arch Neur Psych 37: 1298-1321.

28. Fog $\mathrm{T}$ (1963) On the vessel-plaque relations in the brain in multiple sclerosis. Acta Psychiat Neurol Scand 39: 257-226.

29. Allen IV (1981) The pathology of multiple sclerosis--fact, fiction and hypothesis. Neuropathol Appl Neurobiol 7: 169-182.

30. Zamboni P (2006) The big idea: iron-dependent inflammation in venous disease and proposed parallels in multiple sclerosis. J R Soc Med 99: 589-593.

31. Ge Y, Zohrabian VM, Osa EO, Xu J, Jaggi H, et al. (2009) Diminished visibility of cerebral venous vasculature in multiple sclerosis by susceptibility-weighted imaging at 3.0 Tesla. J Magn Reson Imaging 29: 1190-119.

32. Ge Y, Law M, Johnson G, Herbert J, Babb JS, et al. (2005) Dynamic susceptibility contrast perfusion MR imaging of multiple sclerosis lesions: characterizing hemodynamic impairment and inflammatory activity. AJNR Am J Neuroradiol 26: 1539-1547.

33. Singh AV, Zamboni P (2009) Anomalous venous blood flow and iron deposition in multiple sclerosis. J Cereb Blood Flow Metab 29: 1867-1878.

34. Zamboni P, Galeotti R, Menegatti E, Malagoni AM, Tacconi G, et al. (2009) Chronic cerebrospinal venous insufficiency in patients with multiple sclerosis. J Neurol Neurosurg Psychiatry 80: 392-399.

35. Minagar A, Jy W, Jimenez JJ, Alexander JS (2006) Multiple sclerosis as a vascular disease. Neurol Res 28: 230-235.

36. Haider L, Fischer MT, Frischer JM, Bauer J, Höftberger R, et al. (2011) Oxidative damage in multiple sclerosis lesions. Brain 134: 1914-1924.

37. Yanagisawa M, Kurihara H, Kimura S, Tomobe Y, Kobayashi M, et al. (1988) A novel potent vasoconstrictor peptide produced by vascular endothelial cells. Nature 332: 411-415.

38. Adams CW (1988) Perivascular iron deposition and other vascular damage in multiple sclerosis. J Neurol Neurosurg Psychiatry 51: 260-265. 